Research Paper

\title{
6-Shogaol attenuates LPS-induced inflammation in BV2 microglia cells by activating PPAR-Y
}

\author{
Qinghe Han' ${ }^{2}$, Qinghai Yuan ${ }^{2}$ and Guanghong Xie ${ }^{1}$ \\ ${ }^{1}$ College of Veterinary Medicine, Jilin University, Changchun 130062, China \\ ${ }^{2}$ The Second Hospital of Jilin University, Changchun 130000, China \\ Correspondence to: Guanghong Xie, email: Xiegh@jlu.edu.cn
}

Keywords: 6-Shogaol, LPS, PPAR-Y, BV2 microglia

Received: November 08, $2016 \quad$ Accepted: March 01, 2017

Published: March 30, 2017

Copyright: Han et al. This is an open-access article distributed under the terms of the Creative Commons Attribution License 3.0 (CC BY

3.0), which permits unrestricted use, distribution, and reproduction in any medium, provided the original author and source are credited.

\section{ABSTRACT}

6-Shogaol, a pungent agent isolated from Zingiber officinale Roscoe, has been known to have anti-tumor and anti-inflammatory effects. However, the antiinflammatory effects and biological mechanism of 6-Shogaol in LPS-activated BV2 microglia remains largely unknown. In this study, we evaluated the anti-inflammatory effects of 6-Shogaol in LPS-activated BV2 microglia. 6-Shogaol was administrated 1 $h$ before LPS treatment. The production of inflammatory mediators were detected by ELISA. The expression of NF-KB and PPAR-Y were detected by western blot analysis. Our results revealed that 6-Shogaol inhibited LPS-induced TNF- $a$, IL-1 $\beta$, IL-6, and PGE2 production in a concentration dependent manner. Furthermore, 6-Shogaol inhibited LPS-induced NF-KB activation by inhibiting phosphorylation and nuclear translocation of NF-KB p65. In addition, 6-Shogaol could increase the expression of PPAR-y. Moreover, inhibition of PPAR-y by GW9662 could prevent the inhibition of 6-Shogaol on LPS-induced inflammatory mediator production. In conclusion, 6-Shogaol inhibits LPS-induced inflammation by activating PPAR-y.

\section{INTRODUCTION}

The incidence of neurodegenerative disease, particularly Parkinson disease (PD) and Alzheimer's disease, increased markedly in the last decades $[1,2]$. Microglia, the major immune cells in the brain, plays a key role in host defence response to injury or infectious agents [3]. Microglia is exquisitely sensitive to brain injury and disease [4]. Overactivation of microglia leads to the production of inflammatory mediators which plays a critical role in the development of neuroinflammation $[5,6]$. Neuroinflammation has recently been implicated as an important mechanism responsible for the pathological processes of neurodegenerative diseases [7, 8]. Therefore, the identification of agents to inhibit neuroinflammation might be an effective approach for the treatment of neurodegenerative diseases.

6-Shogaol, a pungent agent from Zingiber officinale Roscoe, has been reported to have anti-tumor and antiinflammatory effects. 6-Shogaol has been reported to protect against LPS-induced acute lung injury in mice. Also, 6-Shogaol was found to attenuate neuroinflammation and cognitive deficits in animal models of dementia [9]. Furthermore, 6-Shogaol has been reported to inhibit LPSinduced iNOS and COX-2 expression in macrophages [10]. In addition, studies showed that 6-Shogaol could protect against LPS-induced toxicity in murine astrocytes [11]. However, whether 6-Shogaol could inhibit LPSinduced anti-inflammatory response in activated microglial cells remains unclear. In the present study, we evaluated the anti-inflammatory effects of 6-Shogaol in LPS-stimulated BV2 microglia.

\section{RESULTS}

Effects of 6-Shogaol on cell viability

To test whether 6-Shogaol has cytotoxicity on BV2 microglia, MTT assay were used in this study. The results showed that 6-Shogaol had no cytotoxicity on BV2 
microglia at the concentration of 0 to $20 \mu \mathrm{g} / \mathrm{mL}$ (Figure 1 ). Therefore, 6-Shogaol $(5,10,20 \mu \mathrm{g} / \mathrm{mL})$ were used in the following experiments.

\section{6-Shogaol inhibited LPS-induced TNF- $\alpha$, IL-1ß, IL-6, and $\mathrm{PGE}_{2}$ production}

To investigate the anti-inflammatory effects of 6-Shogaol, the expression of inflammatory mediators were detected in this study by ELISA. As shown in Figure 2, LPS dramatically increased the production of TNF- $\alpha$, IL-1ß, IL-6, and $\mathrm{PGE}_{2}$. However, 6-Shogaol concentration dependently down-regulated the production of TNF- $\alpha$, IL-1 13 , IL- 6 , and $\mathrm{PGE}_{2}$ induced by LPS.

\section{6-Shogaol inhibited LPS-induced NF-кB activation}

$\mathrm{NF}-\kappa \mathrm{B}$ has been known to be involved in the regulation of inflammatory mediators. To investigate the anti-inflammatory mechanism of 6-Shogaol, LPS-induced $\mathrm{NF}-\kappa \mathrm{B}$ activation were detected in the present study. The results showed that LPS significantly up-regulated the phosphorylation levels of NF- $\kappa \mathrm{B}$ p65 and $\mathrm{I} \kappa \mathrm{B} \alpha$. Pretreatment of 6-Shogaol concentration dependently inhibited LPS-induced NF- $\kappa \mathrm{B}$ p65 phosphorylation and $\mathrm{I} \kappa \mathrm{B} \alpha$ phosphorylation and degradation (Figure 3 ).

\section{Effects of 6-Shogaol on PPAR- $\gamma$ expression}

Previous studies showed that activation PPAR- $\gamma$ could inhibit LPS-induced NF- $\mathrm{BB}$ activation. Thus, we detected whether 6-Shogaol could up-regulated the expression of PPAR- $\gamma$. As shown in Figure 4, 6-Shogaol increased the expression of PPAR- $\gamma$ in a concentration dependent manner (Figure 4).

\section{GW9662 prevented the anti-inflammatory effects of 6-Shogaol}

To further evaluate the anti-inflammatory mechanism of 6-Shogaol, PPAR- $\gamma$ was blocked by its inhibitor GW9662. As shown in Figure 5, our results indicated that the inhibition of 6-Shogaol on TNF- $\alpha$, IL-1ß, IL- 6 and PGE $_{2}$ production were prevented by GW9662. These results suggested that 6-Shogaol exhibited anti-inflammatory effects in BV2 microglia by activating PPAR- $\gamma$.

\section{DISCUSSION}

Microglia has been known to play an important role in neurodegenerative diseases [12]. Increasing evidences suggested that controlling the activation of microglia may have protective effects against neurodegenerative diseases [13]. In this study, the results showed that 6-Shogaol inhibited LPS-induced microglia activation by activating PPAR- $\gamma$.

Microglia, the prime effector cells in the brain, plays a critical role in immune defense and inflammatory responses [14]. However, overactivation of microglia could lead to the pathological process of neurodegenerative diseases [15]. LPS has the ability to induce microglia activation, which lead to the release of inflammatory mediators $[12,16]$. These inflammatory mediators, such as TNF- $\alpha$, IL-1ß, IL-6 and PGE play an important role in the pathological process of

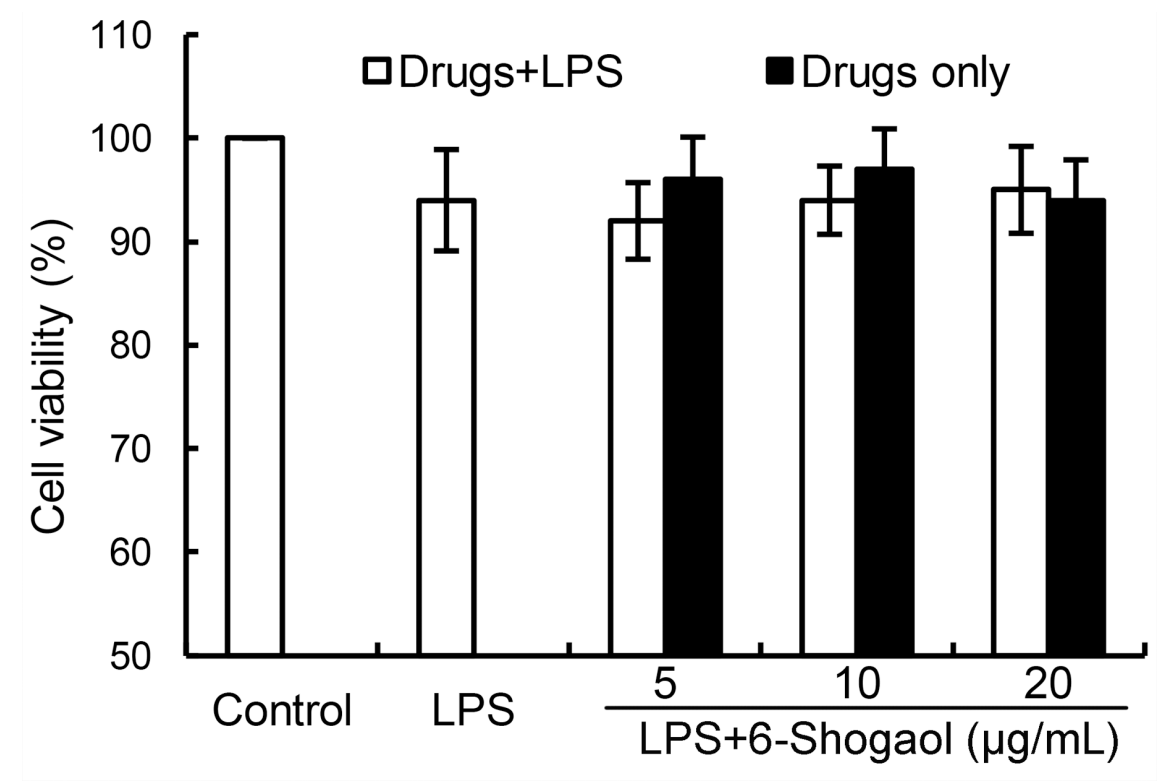

Figure 1: Effects of 6-Shogaol on the cell viability of BV2 microglial cells. Cells were cultured with different concentrations of 6-Shogaol $(5,10,20 \mu \mathrm{g} / \mathrm{ml})$ in the absence or presence of $0.5 \mu \mathrm{g} / \mathrm{mL}$ LPS for $24 \mathrm{~h}$. The cell viability was determined by MTT assay. The values presented are the means \pm SEM of three independent experiments. 
neurodegenerative diseases [17]. In the present study, our results showed that 6-Shogaol significantly inhibited LPS-induced inflammatory mediators production in BV2 microglia. The results indicated that 6-Shogaol exhibited anti-inflammatory effects in BV2 microglia.

It has been reported that NF- $\mathrm{B}$ played a critical role in neuroinflammation [18]. LPS could induce NF$\kappa \mathrm{B}$ activation and inflammatory cytokines release [19].
Inhibition of LPS-induced NF- $\mathrm{B}$ activation could attenuate neuroinflammation [20]. To clarify the antiinflammatory mechanism of 6-Shogaol, NF- $\kappa$ B activation were measured in this study. We demonstrated that 6-Shogaol significantly inhibited LPS-induced NF$\kappa \mathrm{B}$ activation. PPAR- $\gamma$, belongs to a nuclear receptor superfamily, is a ligand-activated transcription factor [21]. Activation of PPAR- $\gamma$ could regulate metabolism
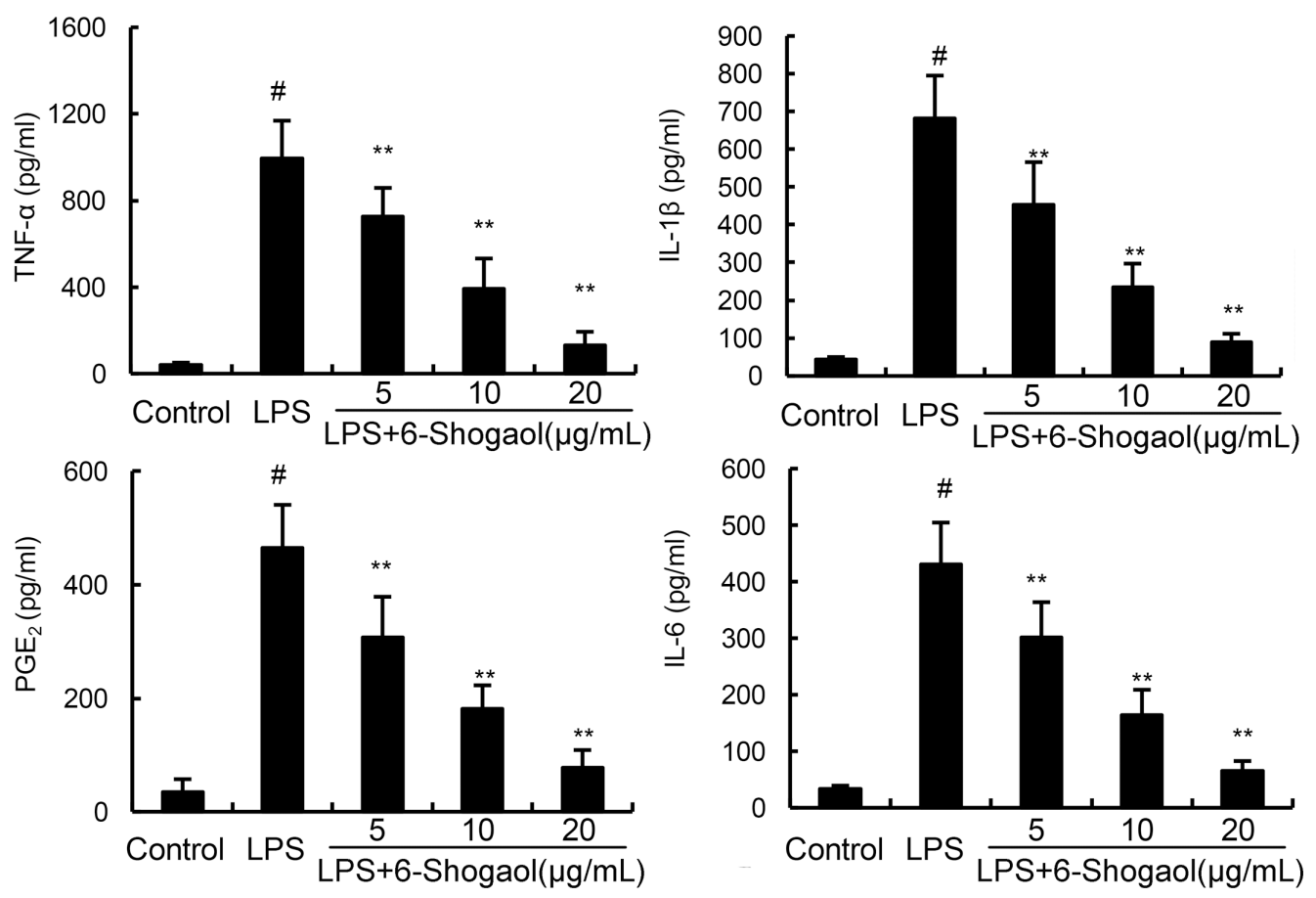

Figure 2: Effects of 6-Shogaol on LPS-induced TNF- $\alpha$, IL-1ß, IL-6 and PGE $\mathbf{2}$ production. The production of TNF- $\alpha$, IL-1 IL-6 and PGE 2 were measured by ELISA. The data presented are the means \pm SEM of three independent experiments. ${ }^{\#} p<0.05 v s$. control group; $* p<0.05, * * p<0.01 v s$. LPS group.
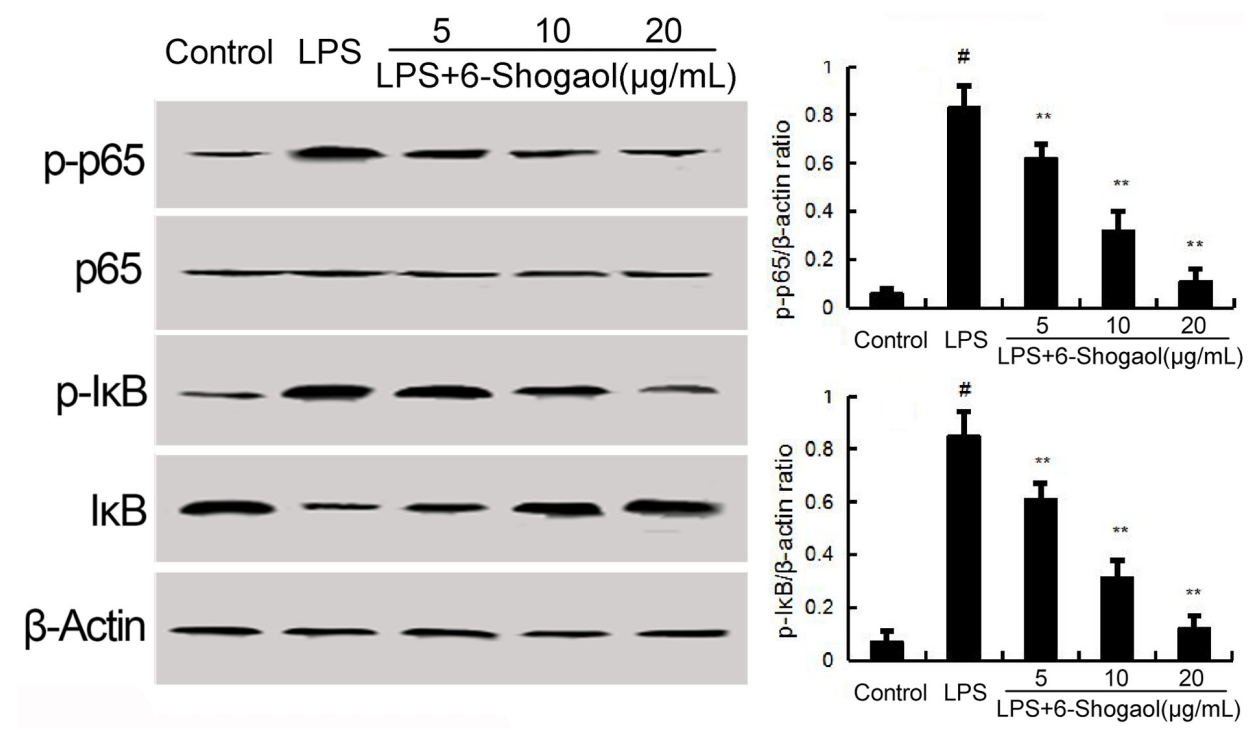

Figure 3: Effects of 6-Shogaol on NF-кB expression. The values presented are the means \pm SEM of three independent experiments. ${ }^{\#} p<0.05$ vs. control group; $* p<0.05, * * p<0.01$ vs. LPS group. 
and inflammation [22]. Previous studies PPAR- $\gamma$ agonists inhibited LPS-induced airway inflammation [23]. Also, PPAR- $\gamma$ agonists could suppress LPSinduced inflammatory response in RAW264.7 cells [24].
Furthermore, PPAR- $\gamma$ agonists have been reported to have therapeutic role in diabetes, inflammation, and cancer [25]. In this study, our results showed that 6-Shogaol increased the expression of PPAR- $\gamma$. And GW9662, a PPAR- $\gamma$

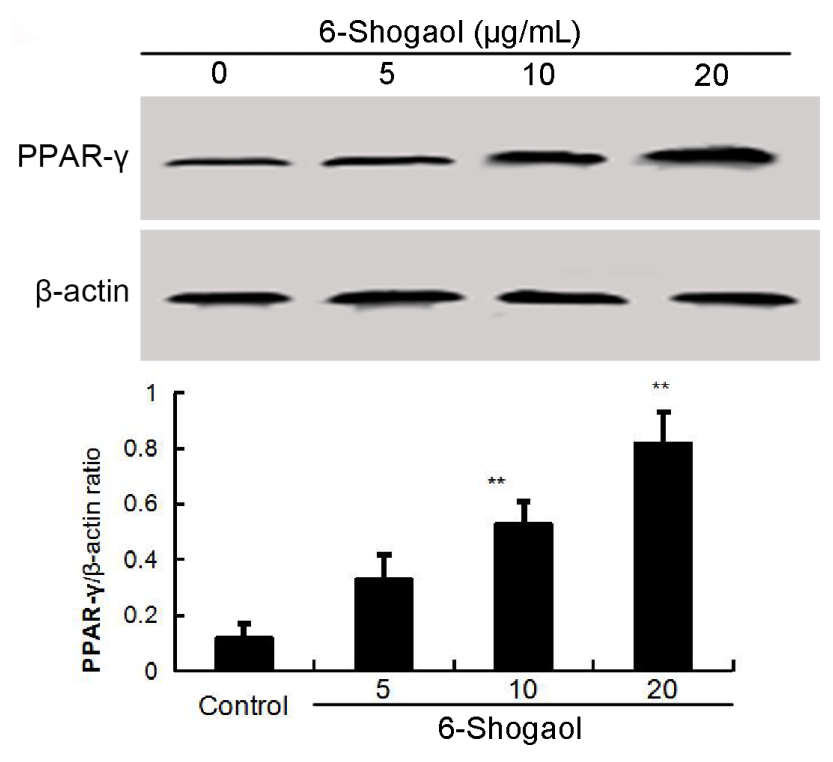

Figure 4: Effects of 6-Shogaol on PPAR- $\gamma$ expression. The values presented are the means \pm SEM of three independent experiments. ${ }^{\#} p<0.05 v s$. control group; ${ }^{*} p<0.05, * * p<0.01 v s$. LPS group.
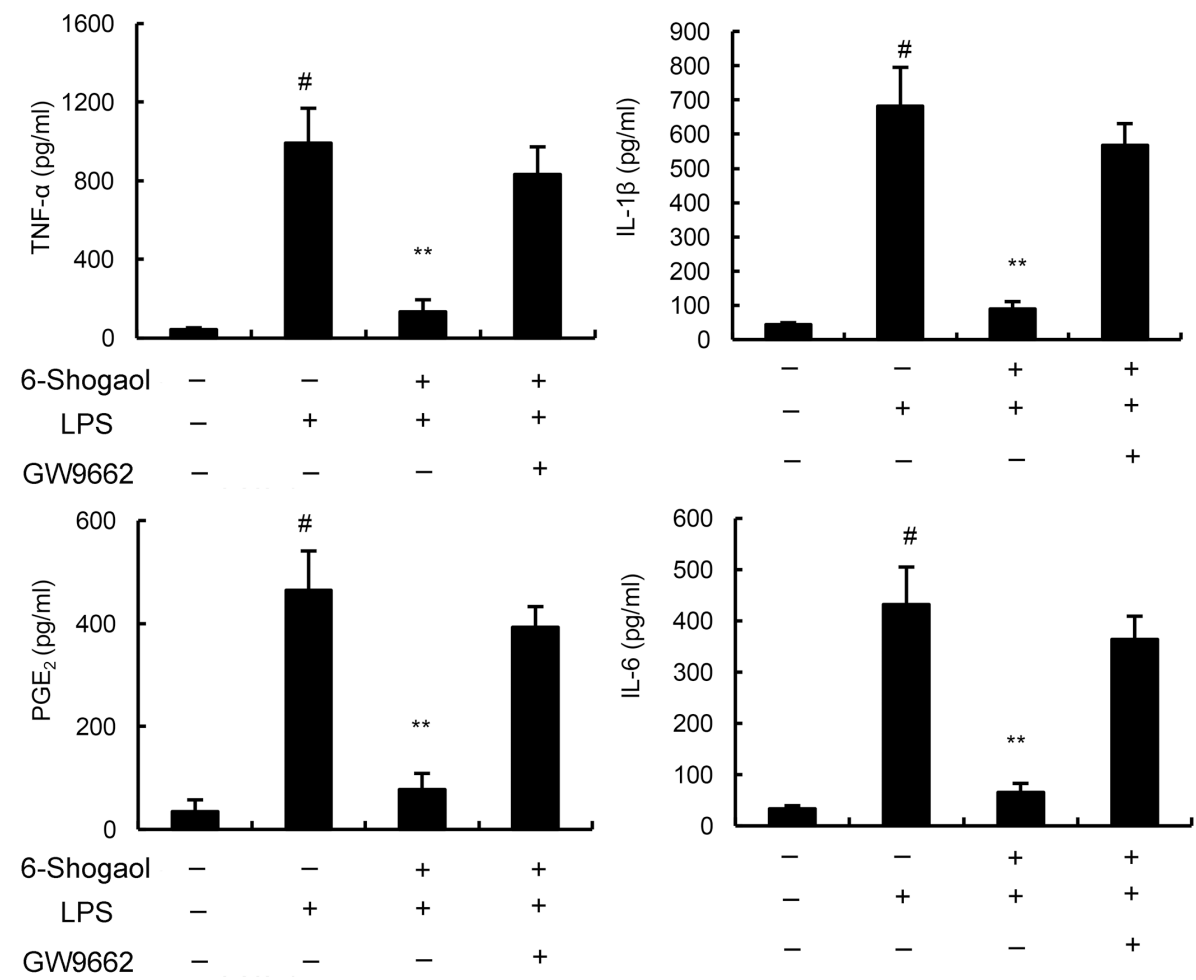

Figure 5: Effects of PPAR- $\gamma$ inhibitor GW9662 on the anti-inflammatory effects of 6-Shogaol. Cells were treated with GW9662 for $12 \mathrm{~h}$. Then, the cells were treated with 6-Shogaol and stimulated by LPS. The productions of inflammatory mediator were detected $24 \mathrm{~h}$ after LPS treatment. The values presented are the means \pm SEM of three independent experiments. ${ }^{\#} p<0.05 v s$. control group; ${ }^{*} p<0.05, * * p<0.01$ vs. LPS group. 
inhibitor, could prevent the inhibition of 6-Shogaol on TNF- $\alpha$, IL-1ß, IL- 6 and PGE 2 production. These results indicated that 6-Shogaol exhibited anti-inflammatory effects in BV2 microglia by activating PPAR- $\gamma$.

In conclusion, our results demonstrated that 6-Shogaol suppressed LPS-induced inflammatory mediators production by activating PPAR- $\gamma$, which subsequently inhibited LPSinduced NF- $\kappa$ B activation. 6-Shogaol might be an effective agent for the treatment of neurodegenerative diseases.

\section{MATERIALS AND METHODS}

\section{Materials}

6-Shogaol (purity $>98 \%$ ) was obtained from the National Institute for the Control of Pharmaceutical and Biological Products (Beijing, China). LPS (Escherichia coli O55:B5) and MTT were purchased from Sigma (St. Louis, MO, USA). ELISA kits of PGE 2 , TNF- $\alpha$, IL-6 and IL-1 $\beta$ were purchased from BioLegend (San Diego, CA). PPAR- $\gamma$ monoclonal antibody was obtained from Santa Cruz Biotechnology (Heidelberg, Germany). NF- $\mathrm{B}$ p65, $\mathrm{I} \kappa \mathrm{B} \alpha$, and $\beta$-actin monoclonal antibodies were obtained from Cell Signaling Technology Inc (Boston, MA, USA).

\section{Cell culture}

Murine BV2 microglia cells were purchased from China Center for Type Culture Collection (CCTCC, Wuhan, China). The cells were cultured in DMEM with $5 \%$ fetal bovine serum, $100 \mathrm{U} / \mathrm{ml}$ penicillin, and $100 \mathrm{mg} / \mathrm{ml}$ streptomycin. The cells were treated with 6-Shogaol $1 \mathrm{~h}$ before LPS treatment.

\section{Cell viability}

For determination of cell viability, MTT assay was applied in this study. BV2 microglia was incubated with 6-Shogaol alone and with LPS for $18 \mathrm{~h}$. Then, the cells were treated with MTT for $4 \mathrm{~h}$ and the formazan formed was dissolved with DMSO $(150 \mu \mathrm{l} /$ well). The optical density was determined at $570 \mathrm{~nm}$ using a Bio-Rad spectrophotometer.

\section{ELISA assay}

$24 \mathrm{~h}$ after LPS treatment, the levels of TNF- $\alpha$, IL-1 $\beta$, IL-6, and PGE2 in culture media were tested using commercially available ELISA kits (BioLegend, San Diego, CA). The assay was performed following the instructions provided by the manufacturers.

\section{Western blot analysis}

The cells were lysed using RIAP lysis buffer and the concentration was measured by BCA method. Equal amount of protein was resolved using 12\% SDS- polyacrylamide gel. The proteins were transferred onto PVDF membranes. The membranes were blocked with $5 \%$ skimmed milk and incubated with primary antibodies and HRP-conjugated goat anti-rabbit IgG. The proteins were tested using the chemiluminescence detection system (Amersham, Berkshire, UK). Finally, the bands were analyzed using ImageJ software.

\section{Statistical analysis}

Data were presented as means \pm SEM. Statistical comparison of the data were analyzed by one-way ANOVA with post-test Neuman-Keuls. A $p$ value $<0.05$ was considered as significant.

\section{CONFLICTS OF INTEREST}

All authors declare that they have no conflicts of interest.

This study was supported by grants from the National Natural Science Foundation of China (No. 31672616) and 2016 Open fund project of State Key Laboratory of food science and technology of Nanchang university (SKLF-KF-201614).

\section{REFERENCES}

1. Tanzi RE, Bertram L. Twenty years of the Alzheimer's disease amyloid hypothesis: a genetic perspective. Cell. $2005 ; 120: 545-555$.

2. Driver JA, Logroscino G, Gaziano JM, Kurth T. Incidence and remaining lifetime risk of Parkinson disease in advanced age. Neurology. 2009; 72:432-438.

3. Liu B, Hong JS. Role of microglia in inflammationmediated neurodegenerative diseases: mechanisms and strategies for therapeutic intervention. J Pharmacol Exp Ther. 2003; 304:1-7.

4. Rock RB, Gekker G, Hu S, Sheng WS, Cheeran M, Lokensgard JR, Peterson PK. Role of microglia in central nervous system infections. Clinical microbiology reviews. 2004; 17:942-964.

5. Hanisch UK. Microglia as a source and target of cytokines. Glia. 2002; 40:140-155.

6. Block ML, Hong JS. Microglia and inflammation-mediated neurodegeneration: Multiple triggers with a common mechanism. Prog Neurobiol. 2005; 76:77-98.

7. Glass CK, Saijo K, Winner B, Marchetto MC, Gage FH. Mechanisms Underlying Inflammation in Neurodegeneration. Cell. 2010; 140:918-934.

8. Zipp F, Aktas O. The brain as a target of inflammation: common pathways link inflammatory and neurodegenerative diseases. Trends Neurosci. 2006; 29:518-527.

9. Moon M, Kim HG, Choi JG, Oh H, Lee PK, Ha SK, Kim SY, Park Y, Huh Y, Oh MS. 6-Shogaol, an active constituent of ginger, attenuates neuroinflammation and 
cognitive deficits in animal models of dementia. Biochem Biophys Res Commun. 2014; 449:8-13.

10. Pan MH, Hsieh MC, Hsu PC, Ho SY, Lai CS, Wu H, Sang SM, Ho CT. 6-Shogaol suppressed lipopolysaccharideinduced up-expression of iNOS and COX-2 in murine macrophages. Mol Nutr Food Res. 2008; 52:1467-1477.

11. Shim S, Kim S, Kwon YB, Kwon J. Protection by [6]-shogaol against lipopolysaccharide-induced toxicity in murine astrocytes is related to production of brain-derived neurotrophic factor. Food Chem Toxicol. 2012; 50:597-602.

12. Dheen ST, Kaur C, Ling EA. Microglial activation and its implications in the brain diseases. Curr Med Chem. 2007; 14:1189-1197.

13. Liu B, Hong JS. Role of microglia in inflammationmediated neurodegenerative diseases: Mechanisms and strategies for therapeutic intervention. J Pharmacol Exp Ther. 2003; 304:1-7.

14. Glezer I, Simard AR, Rivest S. Neuroprotective role of the innate immune system by microglia. Neuroscience. 2007; 147:867-883.

15. Block ML, Zecca L, Hong JS. Microglia-mediated neurotoxicity: uncovering the molecular mechanisms. Nat Rev Neurosci. 2007; 8:57-69.

16. Wang MJ, Lin WW, Chen HL, Chang YH, Ou HC, Kuo JS, Hong JS, Jeng KC. Silymarin protects dopaminergic neurons against lipopolysaccharide-induced neurotoxicity by inhibiting microglia activation. Eur J Neurosci. 2002; 16:2103-2112.

17. Smith JA, Das A, Ray SK, Banik NL. Role of proinflammatory cytokines released from microglia in neurodegenerative diseases. Brain Res Bull. 2012; 87:10-20.

18. Dilshara MG, Jayasooriya RG, Lee S, Choi YH, Kim GY. Morin downregulates nitric oxide and prostaglandin E2 production in LPS-stimulated BV2 microglial cells by suppressing NF-kappaB activity and activating HO-1 induction. Environmental toxicology and pharmacology. 2016 ; 44:62-68.

19. Covert MW, Leung TH, Gaston JE, Baltimore D. Achieving stability of lipopolysaccharide-induced NF-kappaB activation. Science. 2005; 309:1854-1857.

20. Wang YP, Wu Y, Li LY, Zheng J, Liu RG, Zhou JP, Yuan SY, Shang Y, Yao SL. Aspirin-triggered lipoxin A4 attenuates LPS-induced pro-inflammatory responses by inhibiting activation of NF-kappaB and MAPKs in BV-2 microglial cells. Journal of neuroinflammation. 2011; 8:95.

21. Yessoufou A, Wahli W. Multifaceted roles of peroxisome proliferator-activated receptors (PPARs) at the cellular and whole organism levels. Swiss Med Wkly. 2010; 140:w13071.

22. Chawla A, Barak Y, Nagy L, Liao D, Tontonoz P, Evans RM. PPAR-gamma dependent and independent effects on macrophage-gene expression in lipid metabolism and inflammation. Nat Med. 2001; 7:48-52.

23. Birrell MA, Patel HJ, McCluskie K, Wong S, Leonard T, Yacoub MH, Belvisi MG. PPAR-gamma agonists as therapy for diseases involving airway neutrophilia. Eur Respir J. 2004; 24:18-23.

24. Huang C, Yang Y, Li WX, Wu XQ, Li XF, Ma TT, Zhang L, Meng XM, Li J. Hyperin attenuates inflammation by activating PPAR-gamma in mice with acute liver injury (ALI) and LPS-induced RAW264.7 cells. Int Immunopharmacol. 2015; 29:440-447.

25. Murphy GJ, Holder JC. PPAR-gamma agonists: therapeutic role in diabetes, inflammation and cancer. Trends Pharmacol Sci. 2000; 21:469-474. 